\title{
Case Report of Lymph Nodal, Hepatic and Splenic Tuberculosis in an HIV-Positive Patient
}

\author{
Bianca Barone $^{1}$, Patrícia Lago Kreuzig ${ }^{1}$, \\ Patricia Medeiros Gusmão ${ }^{1}$, Frederico de C. Escaleira ${ }^{1}$, \\ Daniel Chamié ${ }^{1}$, Sabrina Bezerra ${ }^{1}$, Pedro Pinheiro ${ }^{1}$, \\ Pedro Coscarelli ${ }^{1}$, Daurita Paiva ${ }^{1}$, Leila Fonseca ${ }^{2}$, \\ Anna Marsico ${ }^{3}$, André Cirigliano ${ }^{1}$ and Mário Perez ${ }^{1}$
}

\author{
${ }^{1}$ Hospital Universitário Pedro Ernesto Universitary Hospital \\ (HUPE); ${ }^{2}$ Microbiology Institute, ${ }^{3}$ Thoracic Disease Institute, \\ Federal University of Rio de Janeiro; Rio de Janeiro, RJ, Brazil
}

\begin{abstract}
We describe a case of a male patient, 38 years old, HIV-positive (most recent $\mathrm{CD}_{4}$ count about 259/ $\mathbf{m m}^{3}$ ), with abdominal pain, nausea, vomiting, anorexia, weight loss, and vespertine high fever with chills. His hemogram showed normocytic and normochromic anemia, with a high erythrocyte sedimentation rate (ESR) and gross granulations in the neutrophils. Transaminases were normal. Bone marrow biopsy evidenced a chronic disease anemia pattern and a lack of infectious agents. Abdominal ultrasound examination showed a normal-size spleen, which exhibited heterogeneous parenchyma and multiple small hypoechoic images, together with small ascites, peripancreatic and para-aortic lymphadenopathy. These findings were confirmed by abdominal CT. The liver was normal in size, but had a hyperechoic image, which was not visualized on CT. Histopathological analysis of one of the multiple abdominal lymph nodes obtained by laparoscopic biopsy exhibited a chronic granulomatous inflammatory process, with caseous necrosis. Tissue sections were positive for BAAR (acid-alcohol-resistant bacillus), and the cultures were positive for Mycobacterium tuberculosis. Antituberculosis treatment was begun, and the patient evolved with improvement of his general state, fever remission and weight gain. Splenic tuberculosis is a rare disease, occurring predominantly in patients in late stages of AIDS and/or disseminated tuberculosis. It is a difficult diagnosis, since there are no specific findings. Hence, complementary examinations, such as abdominal ultrasound/ CT, or fine needle aspiration, are usually necessary for investigation and differential diagnosis. Often, lesion regression after anti-tuberculosis regimens can be seen, and splenectomy is restricted to complicated or refractory disease.
\end{abstract}

Key Words: Tuberculosis, HIV, treatment.

The extra-pulmonary presentations of tuberculosis are more frequent in patients with AIDS than in those without HIV infection. [1-7]. Projections show that up to $70 \%$ of patients coinfected with HIV and Mycobacterium tuberculosis will develop at least one extra-pulmonary form of this mycobacteriosis [810]. Under these circumstances, the lymph nodal presentation is the most common, mostly involving peripheral lymph nodes. In abdominal forms, peritoneal [6,11-13] and lymph nodal [8] tuberculosis predominate, and they sometimes are associated with involvement of other solid organs, such as the liver. Splenic tuberculosis is very rare [1,8,14-17]; it occurs predominantly in patients with CD4 counts less than $100 / \mathrm{mm}^{3}[1,18,19]$.

We report a case of an HIV-positive patient with hepatosplenic and lymph nodal forms of tuberculosis.

\section{Case Report}

A 38 year-old man, HIV positive with a most recent $\mathrm{CD}_{4}$ count of $259 / \mathrm{mm}^{3}$ and a viral load of 9,300 copies $/ \mathrm{mm}^{3}$ (nine months before the beginning of the symptoms) was being

Received on 13 December 2005; revised 17 March 2006.

Address for correspondence: Dr. Bianca Barone, M.D., bbarone@terra.com.br - Av. 28 de Setembro, 87/30. andar, enfermaria 17/18 de Clínica Médica - Vila Isabel, Rio de Janeiro/ RJ, Brazil.

The Brazilian Journal of Infectious Diseases 2006;10(2):149-153. (C) 2006 by The Brazilian Journal of Infectious Diseases and Contexto Publishing. All rights reserved. treated with anti-retroviral therapy (stavudine, lamivudine and efavirenz), presenting abdominal pain in the epigastric region that worsened when he ate. He was initially treated with 300 mg ranitidine daily, with transient remission of the pain, which returned after one week; this pain was then associated with nausea, vomiting, anorexia and two isolated episodes of diarrhea without infectious characteristics. After a week, he had begun to present vespertine high fever (about $39^{\circ} \mathrm{C}$ ), with chills, weight loss (about $5 \mathrm{~kg}$ ), eructation and heartburn.

This patient had previously been afflicted with lymph nodal tuberculosis seven years earlier, at the time that he was diagnosed to have HIV infection. At that time, he had been treated with rifampicin, isoniazid and pyrazinamide for six months, which provoked drug-related hepatitis. Despite this drug-related complication, the lymph nodal enlargement had complete resolution. Since then, he had been asymptomatic. The patient was homosexual, with a stable partner, and he denied intravenous drug use.

On clinical examination, the patient was lucid, oriented in time and space, cooperative, wasted, febrile, pale $+/ 4+$, hypotensive, tachycardic, acyanotic, anicteric and normopneic, without peripheral lymphadenopathy or oral candidiasis. Cardiovascular and respiratory examinations were unremarkable. He had abdominal tenderness in the epigastric region, without hepatosplenomegaly.

He brought exams from the day before admission, including a $\mathrm{CD}_{4}$ count of $85 / \mathrm{mm}^{3}$ and a viral load of 1,300 copies/ $\mathrm{mm}^{3}$. 
Pertinent laboratory findings on admission included: hemoglobin $7.23 \mathrm{~g} / \mathrm{dL}$, hematocrit $21.4 \%$, ESR $72 \mathrm{~mm} / \mathrm{h}$, leucocytes $8,120 / \mathrm{mL}$ (immature neutrophils $18 \%$, neutrophils $61.5 \%$, lymphocytes $7.4 \%$, monocytes $12 \%$ ), and platelet count $248,000 / \mathrm{mL}$. A peripheral blood smear showed macrocytosis $(+/ 4+)$, with gross granulations inside the neutrophils. Some squizocytes and a few "hat" red cells were seen. The chest X-ray was normal. Bacteriological cultures of blood, urine and stools were negative. Serum albumin, iron, TIBC and ferritin were, respectively: $2.6 \mathrm{~g} /$ $\mathrm{dL}, 10 \mathrm{mg} / \mathrm{dL}, 150 \mathrm{mmol} / \mathrm{L}$ and $992.62 \mathrm{mg} / \mathrm{dL}$. Serum sodium, total protein, transaminases, lactic dehydrogenase, amylase, glutamictransferase and alkaline phosphatase were normal. Other relevant results were: serum potassium $5.8 \mathrm{mmol} / \mathrm{L}$, urea $95 \mathrm{mg} / \mathrm{dL}$ and creatinine $2.7 \mathrm{mg} / \mathrm{dL}$, which returned to normal range values after parenteral hydration.

Biopsy showed a normocellular bone marrow, with evident maturation of erythroid and myeloid series, and megaloblastosis. There were no infectious agents, nor was there malignancy. Prussian blue staining of the bone marrow showed probable chronic anemia, without mobilizations of iron body stores. Cultures for bacteria, fungi and mycobacteria were negative. Ziehl-Neelsen staining was negative.

Upper gastrointestinal digestive endoscopy showed mild active chronic atrophic gastritis. The specimen was negative for Helicobacter pylori and/or malignancies. On abdominal ultrasonography, there were small ascites, without hepatomegaly, but with an hyperechogenic image

Figure 1. Abdominal CT showing multiple hypodense images in splenic parenchyma (two indicated by yellow arrows), associated with retroperitoneal enlarged lymph nodes, with peripheral enhancement and low-attenuation spots at the centers of the nodes (red arrows). on the upper region of the left lobe, of about $1.8 \mathrm{~cm}$. The spleen was also normal in size, but with heterogeneous parenchyma and multiple small hypoechogenic images, with peripancreatic and para-aortic lymphadenopathy. Abdominal CT revealed multiple retroperitoneal lymph nodes, with peripheral enhancement and low-attenuation spots at the centers of the nodes (Figure 1). We could not see any hepatic lesions. Laparoscopy showed liver and spleen with multiple plain lesions on the surface, about 2$3 \mathrm{~mm}$ in size. There was lymphadenopathy in the hepatic hilum and para-aortic chains. The patient was submitted to a laparoscopic biopsy of one of the multiple abdominal lymph nodes. Hystopathological analysis was characterized by a chronic granulomatous inflammatory process, with giant cells, caseous necrosis and cells containing acid-fast bacilli (Figure 2). Culture of the tissue specimen was positive for Mycobacterium tuberculosis. The bacterial strain was susceptible to all antituberculosis drugs tested (rifampicin, isoniazid, ethambutol, streptomycin and ethionamid). We began antituberculous medication (rifampicin, isoniazid and pyrazinamide), and the patient evolved with improvement of general state, fever remission and weight gain, without complicating hepatitis. The patient was treated for nine months; follow-up ultrasonography was then performed, showing complete resolution of splenic abscesses, with calcifications still visible.

Figure 2. (2a) Paraffin section of an abdominal lymph node, showing a granulomatous reaction with many giant cells (arrows) and caseous necrosis (asterisk) (HE). (2b) Some cells contained acid-fast bacilli (arrows).
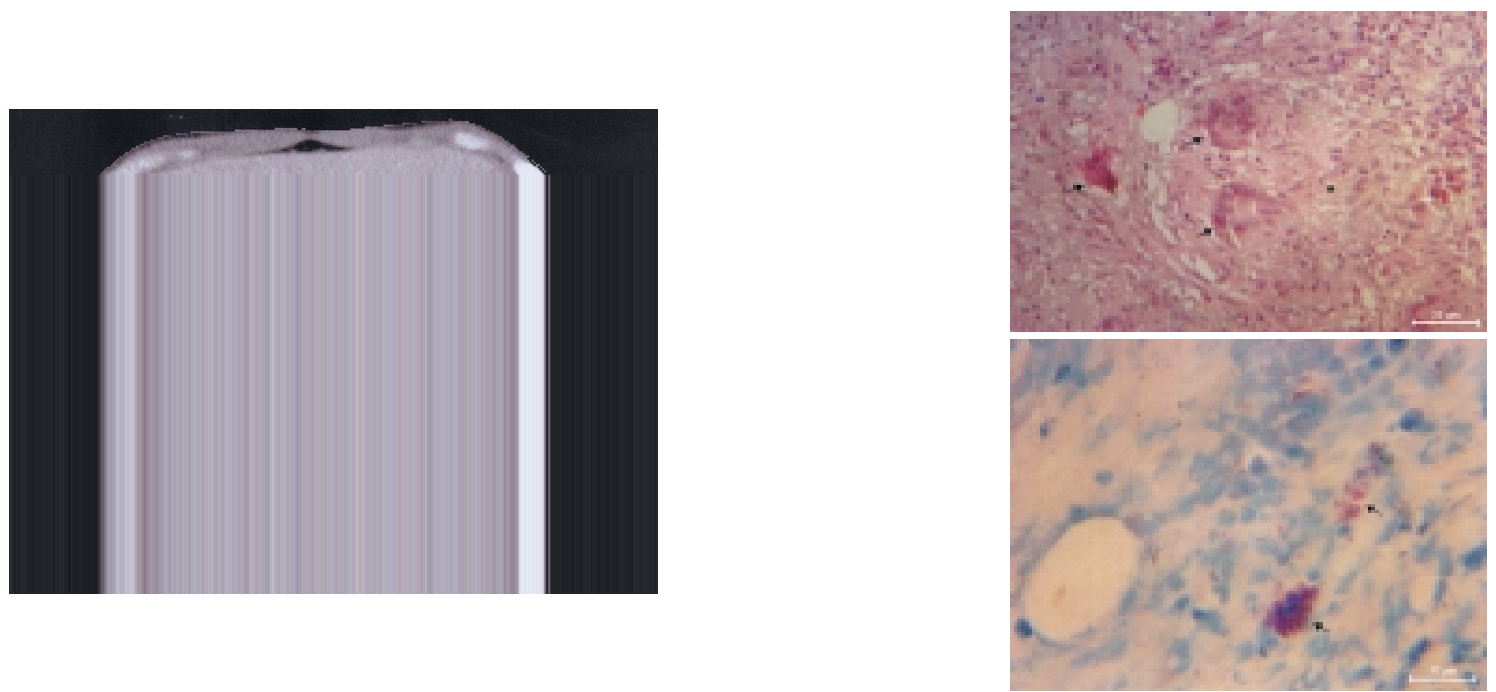


\section{Discussion}

In recent years, splenic tuberculosis case reports have come from areas with a high incidence of both HIV and tuberculosis, such as South Africa. However, reports of this presentation of the disease have also been made in Central Europe [20,21] and in other regions [22].

In Brazil, among AIDS reports notified by the Health Ministry, tuberculosis is the third commonest co-infection (24\%), only surpassed by candidiasis (54\%) and by Pneumocystis jeruveci pneumonia [23]. Tuberculosis may act as a co-factor that accelerates the clinical course of the HIV infection, which reduces survival more in HIV-positive than in seronegative patients [24].

Some studies have shown that splenic tuberculosis in HIVpositive patients is associated with intravenous drug use [1], which was not true in our patient. Splenic involvement is common in the milliary or disseminated forms of this mycobacteriosis [25], especially in HIV-positive patients with extra-pulmonary tuberculosis [1,26-28], but this isolated form of presentation is very rare $[1,8,14]$.

Splenic tuberculosis is, generally, a difficult diagnosis, since there are no specific findings. Splenomegaly, pyrexia of unknown origin, with chills, weight loss, anorexia, diarrhea, abdominal pain, ascites, cough and lymphadenopathy, are some of the clinical findings of splenic tuberculosis in HIVpositive patients $[1,8,26,29-40]$. There are few reports of spontaneous splenic rupture due to this mycobacterial infection, causing acute abdominal pain (both in HIV-positive patients and in otherwise normal individuals) [14]; there are also few reports of hypersplenism with bleeding tendencies (petechiae, purpura, ecchymoses) [15-17,41,42]. Since clinical findings are unspecific, complementary exams are needed for clinical investigation and differential diagnosis in relation to other splenic lesions that can be seen in patients who have AIDS, such as other opportunistic infections $[1,8,26,27,29,30$ 40], lymphomas and splenic Kaposi's sarcoma [1].

Among the complementary examinations that help diagnose splenic tuberculosis, abdominal ultrasonography and CT are the most informative. On abdominal ultrasound examination, the most suggestive findings are multiple small $(<1 \mathrm{~cm})$, round hypoechogenic images, which are frequently hypodense on abdominal CT [6,8,11,21,26,43-50]. Splenomegaly [6,27,51-54] is also seen, and it is considered to be the most common feature of splenic involvement [55]. However, some reports point out the possibility of presentation with uniloculated pseudotumoral macronodules [5,6,11,22,46,56,57]. A hyperechogenic nodule, with or without calcification, has also been described $[6,58,59]$. Relative leucocytosis is another unspecific finding in splenic tuberculosis [21]. In some cases, it is possible to attain a final diagnosis by isolating Mycocabterium tuberculosis in blood cultures [8]. Unfortunately, when the spleen is the only organ affected, the final diagnosis is generally made by histopathological examination, using specimens obtained with laparotomy or percutaneous fine needle aspiration [26,45,60-63].

The fact that HIV patients with splenic tuberculosis have lower $\mathrm{CD}_{4}$ counts at the moment of diagnosis does not usually imply a poor prognosis. On the contrary, regression of the splenic lesions occurs only with specific drug treatment (triple drug regimen: rifampicin, isoniazid and pyrazinamide), and the time of treatment is not different from that proposed for the pulmonary forms (RFP, plus INH and PZA: two months; RFP plus INH: four months). Total resolution of splenic lesions may occur with this regimen. Some authors suggest that antituberculosis treatment should be extended for 12 months, since patients often have the generalized form of this mycobacteriosis, even if initially presenting isolated splenic involvement [64]. As with other forms of tuberculosis, the time of treatment of the hepatosplenic form is similar to that proposed for non-HIV patients. However, when the acid-fast sputum smear takes a long time to become negative (i.e.; after two to three months of anti-tuberculous treatment), treatment should be maintained for nine months $[65,66]$.

Some antiretroviral drugs have important interactions with anti-tuberculosis drugs, especially protease inhibitors and non-nucleoside reverse-transcriptase inhibitors, such as rifampicin and rifabutin. Treating tuberculosis should have priority, sometimes requiring changes in antiretroviral regimens. Patients already on antiretroviral therapy should have their regimen adapted to a compatible one during tuberculosis treatment. As soon as anti-tuberculosis drugs can be stopped, the drugs used before the diagnosis of tuberculosis can be reintroduced, depending on the patient's health status. In the case of recently-diagnosed HIV infection, there are two possibilities. The first one is to delay the introduction of antiretroviral therapy until the end of tuberculosis treatment; this strategy is easier, as it can reduce toxicity and eventual interactions between antiretroviral and anti-tuberculous drugs. The disadvantage of this option is the possibility of appearance of other HIV-related diseases during tuberculosis treatment, especially in patients with advanced stages of immunodeficiency, since tuberculosis causes an increase of HIV-viral load and/or a decrease in $\mathrm{CD}_{4}$ count. The second option is to introduce the antiretroviral therapy a few months after the start of antituberculosis drugs, since the side effects of these antituberculosis drugs are more intense during the first months of use. This is the best option in the case of patients with a $\mathrm{CD}_{4}$ count under $200 / \mathrm{mm}^{3}$ or with disseminated forms of tuberculosis. However, if the $\mathrm{CD}_{4}$ count is very low, or there are manifestations of advanced immunodeficiency, the best choice is to start the antiretroviral regimen as soon as the tolerance to anti-tuberculous drugs has been established. The main antiretroviral regimens recommended during the treatment of tuberculosis are the association of two nucleoside reversetranscriptase inhibitors with efavirenz or with the combination saquinavir/ ritonavir. During pregnancy, efavirenz is 
contraindicated; nevirapine should replace this drug in such circumstances $[65,66]$.

Follow-up ultrasonography 20 days - 22 months after the splenic tuberculosis diagnosis should be made, with the intention to verify complete resolution of splenic abscesses $[1,19,21,27]$. In refractory cases, splenectomy is proposed $[1,21,26,27,32,35,37,39,40]$. Few studies report the use of corticoid adjuvant treatment in slow-responding cases, with the intention to prevent an eventual need for therapeutic splenectomy $[8,19]$.

Splenic rupture is another absolute indication for splenectomy in primary treatment of splenic tuberculosis, but anti-tuberculous drugs must be used as complementary treatment. In these cases, conservative surgeries should not be proposed, due to the fragility of splenic tissue and the high risk of recurrence [14].

\section{Acknowledgements}

The authors are indebted to Dr. Marcelo Pelajo-Machado (Department of Pathology - Instituto Oswaldo Cruz FIOCRUZ, Rio de Janeiro/ RJ, Brazil) for constructive comments and for technical support.

\section{References}

1. Gonzalez-Lopez A., Dronda F., Alonso-Sanz M., et al. Clinical significance of splenic tuberculosis in patients infected with human immunodeficiency virus. Clin Infect Dis 1997;24(6): 1248-51.

2. Dubey S.G., Shah N.M., Dayavathi Mangat G.K., Set al. Tubercular splenic abscesses in a patient with AIDS. J Assoc Physicians India 1996;44(8):575-7.

3. Raviglione M.C., O’Brien R.J. Tuberculose. In: Braunwald E., Fauci A.S., Kasper D.L., Hauser S.L., Longo D.L., Jameson J.L. eds. Harrison Medicina Interna, McGraw-Hill, 2002.

4. Snider D.E. Tuberculosis statistics: state and cities, U.S. Department of Human Services/ Public Health Service, Communicable Disease Control, CDC 84-8249: 3-9, 19821987, 1988.

5. Monilla-Serra J.M., Martinez-Noguera A., Montserrat E., et al. Abdominal ultrasound findings of disseminated tuberculosis in AIDS. J Clin Ultrasound 1997;25:1-6.

6. Akhan O., Pringot J. Imaging of abdominal tuberculosis. Eur Radiol 2002;12(2):312-23.

7. Theuer C.P., Hopewell P.C., Elias D., et al. Human immunodeficiency virus infection in tuberculosis patients. $\mathrm{J}$ Infect Dis 1990;162(1):8-12.

8. Salazar A., Carratala J., Santin M., et al. Abscesos esplénicos por Mycobacterium tuberculosis en el SIDA. Enferm Infecc Microbiol Clin 1994;12(3):146-9.

9. Lupatkin H., Brau N., Flomenberg P., Simberkoff M.S. Tuberculous abscesses in patients with AIDS. Clin Infect Dis 1992;14(5):1040-4.

10. Murray J.F. Cursed duet: HIV infection and tuberculosis. Respiration 1990;57(3):210-20.

11. Malik A., Saxena N.C. Ultrasound in abdominal tuberculosis. Abdom Imaging 2003;28:574-9.
12. Batra A., Gulati M.S., Sarma D., Paul S.B. Sonografic appearances in abdominal tuberculosis: comparison of sonography and computed tomography. J Clin Ultrasound 1995;23:413-7.

13. Marshall J.B. Tuberculosis of the gastrointestinal tract and peritoneum. Am J Gastroenterol 1993;88(7):989-99.

14. Pramesh C.S., Tamhankar A.P., Rege S.A., Shah S.R. Splenic Tuberculosis and HIV-1 infection. Lancet 2002;359:353.

15. Chaundhury T., Ghosh G., Ghosh U.S., Banerjee P. Splenic tucerculosis - a case report. J Indian Med Assoc 1998; $96: 317$.

16. Levin M. Acute hypersplenism and thrombocytopenia: a new presentation of disseminated mycobacterial infection in patients with acquired immunodeficiency syndrome. Acta Haematol 1994;91:28-31.

17. Skinner R., Appleton A.L., Sportt S., et al. Disseminated BCG infection in severe combined immunodeficiency presenting with severe anaemia and associated with gross hypersplenism after bone marrow transplantation. Bone Marrow Transplant 1996; $17: 877-80$.

18. Jones B.E., Young S.M., Antoniskis D., et al. Relationship of the manifestations of tuberculosis to CD4 cell counts in patients with human immunodeficiency virus infection. Am Rev Respir Dis 1993;148(5):1292-7.

19. Valencia M.E., Moreno V., Soriano V., et al. [Tuberculous hepatosplenic abscess, human immunodeficiency virus infection and multiresistant tuberculosis]. Rev Clin Esp 1996;196(12):816-20.

20. Corbett E.L., Watt C.J., Walker N. et al. .The growing burden of tuberculosis: global trends and interactions with the HIV epidemic. Arch Intern Méd 2003;163(9):1009-21.

21. Reichel C., Theisen A., Rockstroh J.K. et al. Splenic abscesses and abdominal tuberculosis in patients with AIDS. Z Gastroenterol 1996;34(8):494-6.

22. Chandra S., Srivastava D.N., Gandhi D. Splenic tuberculosis: an unusual sonographic presentation. Int J Clin Pract 1999;53(4):318-9.

23. Kritski A.F., de Souza G.R.M. Co-infecção por M. tuberculosis e HIV. In: Schechter M., Marangoni D.V. eds. Doenças Infecciosas: Conduta Diagnóstica e Terapêutica. Rio de Janeiro: Guanabara Koogan, 1998.

24. Maserati R., Seminari E., Scudeller L., et al. Successful treatment of spleen tuberculosis in a patient with human immunodeficiency virus infection. Monaldi Arch Chest Dis 1999;54(2):130-2.

25. Slavin R.E., Walsh T.J., Pollack A.D. Late generalized tuberculosis: a clinical pathologic analysis and comparison of 100 cases in the preantibiotic and antibiotic eras. Medicine (Baltimore) 1980;59:352-66.

26. Pedro-Botet J., Maristany M.T., Miralles R., et al. Splenic tuberculosis in patients with AIDS. Rev Infect Dis 1991;13(6):1069-71.

27. Wolff M.J., Bitran J., Northland R.G., Levy I.L. Splenic abscesses due to Mycobacterium tuberculosis in patients with AIDS. Rev Infect Dis 1991;13(3):373-5.

28. Smith M.B., Boyars M.C., Veasey S., Woods G.L. Generalized tuberculosis in the acquired immune deficiency syndrome. Arch Pathol Lab Med 2000;124(9):1267-74.

29. Raviglione M.C. Extrapulmonary pneumocystosis: the first 50 cases. Rev Infect Dis 1990;12(6): 1127-38. 
30. Steeper T.A., Rosenstein H., Weiser J., et al. Bacillary epithelioid angiomatosis involving the liver, spleen, and skin in an AIDS patient with concurrent Kaposi's sarcoma. Am J Clin Pathol 1992;97(5):713-8.

31. Carlioz R., Chanu B., Monsuez J.J., et al. Abcès tuberculeux hépato-spléniques au cours du syndrome d'immunodépression acquis: a propos de deux observations. Ann Med Interne (Paris) 1988;139(7):524-6.

32. Giladi M., Ransohoff K.N., Lovett M.A. Splenic abscesses due to Mycobacterium tuberculosis in patients with AIDS: is splenectomy necessary? Rev Infect Dis 1991; 13(5):1030-1.

33. Soriano V., Tor J., Domenech E., et al. Tuberculosis abdominal en los patientes con syndrome de inmunodeficiencia adquirida. Méd Clin (Barc) 1991;97(4):121-4.

34. Soriano V., Tor J., Adrados M., et al. Multifocal splenic abscesses in AIDS-related tuberculosis. Eur J Med 1992; $1(2): 124$.

35. Lozano F., Gomez-Mateos J., Lopez-Cortes L., Garcia-Bragado F. Tuberculous splenic abscesses in patients with the acquired immune deficiency syndrome. Tubercle 1991;72(4):307-8.

36. De Marco O., Nasfi A., Bacques O., Gamerman H. Abcès splénique tuberculeux chez un malade avec sérolie VIH positive. Presse Médicale 1991;20(39):1946.

37. Khalil T., Uzoaru I., Nadimpalli V., Wurtz R. Splenic tuberculous abscess in patients positive for human immunodeficiency virus: report of two cases and review. Clin Infect Dis 1992;14(6):1265-6.

38. Gutiérrez-Marcos F., Casas E., Miquel J., et al. Abscesos esplênicos por Mycobacterium tuberculosis em pacientes com síndrome de inmunodeficiencia adquirida. Gastroenterol Hepatol 1993;16: 534-6.

39. Fuertes Martin A., Santana Garcia S., Martin Sanchez M.J., Jimenez Lopez A. Abscesos esplénicos tuberculosos en apcientes com sida: dos nuevos casos. Enferm Infecc Microbiol Clin 1995; 13(1): 65.

40. Piersimoni C., De Sio G., Petroni S., et al. Mycobacterium avium and multi-drug-resistant Mycobacterium tuberculosis disseminated mixed infection in a patient with acquired immunodeficiency syndrome. Clin Microbiol Newsletter 1995; 17: 6-7.

41. Winternitz M.C. Tuberculosis of the spleen. Arch Intern Med 1912;9:680-97.

42. Bora P., Gomber S., Agarwal V., Jain M. Splenic tuberculosis presenting as hypersplenism.Ann Trop Paediatr 2001;21(1):86-7.

43. Murray J.G., Patel M.D., Lee S., et al. Microabscesses of the liver and spleen in AIDS: detection with 5-MHz sonography. Radiology 1995;197(3):723-7.

44. Radin D.R. Intraabdominal Mycobacterium tuberculosis versus Mycobacterium avium-intracellulare infections in patients with AIDS: distinction based on CT findings. AJR Am. J Roentgenol 1991;156(3):487-91.

45. Ho P-L., Chim C-S., Yuen, K-Y. Isolated splenic Tuberculosis presenting with pyrexia of unknown origin. Scan J Infect Dis 2000;32:700-1.

46. Kapoor R., Jain A.K., Chaturvedi U., Saha M.M. Case report: ultrasound detection of tuberculomas of the spleen. Clin Radiol 1991;43:128-9.
47. Choi B.I., Im J.G., Han M.C., Lee H.S. Hepatosplenic tuberculosis with hypersplenism: CT evaluation. Gastrointest Radiol 1989; 14(3):265-7.

48. Topal U., Savci G., Sadikoglu M.Y., et al. Splenic involvement of tuberculosis: US and CT findings. Eur Radiol 1994;4:577-9.

49. Tritou I., Prassopoulos P., Daskalogiannaki M., et al. Miliary hepatic tuberculosis not associated with splenic or lung involvement. A case report. Acta Radiol 2000;41(5):479-81.

50. Levine C. Primary macronodular hepatic tuberculosis: US and CT appearances. Gastrointest Radiol 1990;15(4):307-9.

51. Bhansali S.K. Abdominal tuberculosis. Experiences with 300 cases. Am J Gastroenterol 1977;67(4):324-37.

52. Hulnick D.H., Megibow A.J., Naidich D.P., et al. Abdominal tuberculosis: CT evaluation. Radiology 1985;157(1):199-204.

53. Dahlene D.H.Jr., Stanley R.J., Koehler R.E., Shin M.S., Tishler J.M. Abdominal tuberculosis: CT findings. J Comput Assist Tomogr 1984;8(3):443-5.

54. Ramaiya L.I., Walter D.F., Walter R. Sonographic features of tuberculous peritonitis. Abdom Imaging 1993;18(1):23-6.

55. Lundstedt C., Nyman R., Brismar J., et al. Imaging of tuberculosis. II. Abdominal manifestations in 112 patients. Acta Radiol 1996;37(4):489-95.

56. Abitbol V., Paupard T., Etienney I., et al. Clinical and radiological aspects of tuberculous splenic abscesses. Presentation of 3 cases. Gastroenterol Clin Biol 1996;20(6-7):597-600.

57. Thoeni R.F., Margulis A.R. Gastrointestinal tuberculosis. Semin Roentgenol 1979;14(4):283-94.

58. Denton T., Hossain J. A radiological study of abdominal tuberculosis in a Saudi population, with special reference to ultrasound and computed tomography. Clin Radiol 1993;47(6):409-14.

59. Brauner M., Buffard M.D., Jeantils V., et al. Sonography and computed tomography of macroscopic tuberculosis of the liver. J Clin Ultrasound 1989; 17(8):563-8.

60. Mahi M., Chaouir S., Amil T., et al. [Isolated tuberculosis of the spleen. Report of a case]. J Radiol 2002; 83(4 Pt 1):479-81.

61. Adil A., Chikhaoui N., Ousehal A., Kadiri R. La tuberculose splenique. A propôs de douze cas. Ann Radiol Paris 1995;38:403-7.

62. Suri R., Gupta S., Gupta S.K., et al. Ultrasound guided fine needle aspiration cytology in abdominal tuberculosis. Braz $\mathrm{J}$ Radiol 1998;71:723-7.

63. Venkataramu N.K., Gupta S., Sood B.P., et al. Ultrasound guided fine needle aspiration biopsy of splenic lesions. Brit J Radiol 1999;72:953-6.

64. Bass J.B.Jr., Farer L.S., Hopewell P.C., et al. Treatment of tuberculosis and tuberculosis infection in adults and children. American Thoracic Society and The Centers for Disease Control and Prevention. Am J Respir Crit Care Med 1994;149:1359-74.

65. (Ministério da Saúde). Terapia Anti-retroviral e Tuberculose. In: Recomendações para a Terapia anti-Retroviral em Adultos e Adolescentes infectados pelo HIV - 2004. Ministério da Saúde, Secretaria de Vigilância em Saúde, Programa Nacional de DST e AIDS. Brasília, 2004.

66. Rachid M., Schechter M. Manifestações Respiratórias. In: Rachid M., Schechter M. (eds.) Manual de HIV/AIDS, $8^{\text {a }}$ edição, Rio de Janeiro: Revinter, 2005. 